\title{
EVALUASI KERJA PERTUMBUHAN DIATOM (Thalassiosira sp) YANG DIBERI DOSIS SILIKAT
}

\author{
Ferdian Sanjaya, Edward Danakusuma \\ Fakultas Perikanan Dan Ilmu Kelautan \\ E-mail: ferdian.sanjaya@gmail.com
}

\begin{abstract}
ABSTRAK
Diatom merupakan mikroalga uniseluler yang distribusinya sangat universal di semua tipe perairan. Diatom memiliki bentuk kehidupan yang kosmopolit dan merupakan penyusun utama mikroalga baik di ekosistem perairan tawar maupun laut dengan jumlah spesies terbesar dibandingkan komunitas mikroalga lainnya. Diatom mempunyai keunikan dan sangat spesifik, karena arsitektur dan anatomi dinding selnya yang tersusun dari silica, menyebabkannya dapat tersimpan dalam kurun waktu yang sangat lama didalam sedimen Tujuan dari penelitian ini yaitu : 1). Mengetahui pertumbuhan diatom (Thalasioseira $\mathrm{sp}$ ) yang di beri dosis silikat. 2). Mengetahui jumlah dosis silikat yang optimum dalam pertumbuhan diatom (Thalasioseira $\mathrm{sp}$ ).

Hasil analisis regresi terhadap rata rata laju pertumbuhan Thallassiosira sp adalah y $=$ 172876x + 163526 dari persamaan ini dapat disimpulkan bahwa rata rata laju pertumbuhan Thallassiosira sp sebesar $172876 \mathrm{mg} / \mathrm{ml}$ dengan dosis yang berbeda yaitu $0 \mathrm{ppm}, 3 \mathrm{ppm}, 6 \mathrm{ppm}$, 9 ppm, 12 ppm, 15 ppm. Hubungan antara kandungan silikat dengan jumlah sel $\mathrm{R}^{2}=0,9706$ hal tersebut menjelaskan bahwa rata rata laju pertumbuhan Thallassiosira sp sebesar 97,02\% saja dimana 2,08\% dipengaruhi oleh faktor lain.

Kesimpulan dari penelitian ini adalah 1). Pengaruh pemberian dosis silikat yang berbeda terhadap pertumbuhan diatom (Thalasiosira) tidak terlalu signifikan. Terdapat perbedaan pertumbuhan oleh masing-masing perlakuan. Hubungan antara kandungan silikat dengan jumlah sel $\mathrm{R}^{2}=0,9706$ hal tersebut menjelaskan bahwa rata rata laju pertumbuhan Thallassiosira $\mathrm{sp}$ sebesar 97,02 \% artinya Kandungan silikat memiliki peranan penting terhadap jumlah sel diatom. Nilai koefisien 2 determinasi ( $\mathrm{R}$ ) digunakan untuk mengetahui besarnya peranan dari peubah $\mathrm{x}$ terhadap Y. Nilai 2

$\mathrm{R}$ berkisar antara 0-1. 2). hasil pengamatan tersebut data dilihat dari data di atas pada $15 \mathrm{ppm}$ menghasilkan data pertumbuhan dan nilai rata-rata pertumbuhan data lebih tinggi di badingkan 12 ppm, 9 ppm,6 ppm, 3 ppm, 0 ppm.
\end{abstract}

Kata kunci : Diatom, Thalasiosira sp, silika.

\section{PENDAHULUAN}

\section{Latar Belakang}

Indonesia memiliki potensi kelautan yang luar biasa, ditunjukkan dengan garis pantai yang terpanjang di dunia $(81.000 \mathrm{~km})$. Indonesia juga disebut mega biodiversity karena keanekaragaman hayatinya yang sangat besar dibandingkan negara lain. Salah satu keanekaragaman hayati laut Indonesia adalah mikroalga diatom (Isnansetyo dan Kurniastuty, 
1995). Saat ini, sekitar 20-25\% produktivitas primer biomassa di bumi ini dihasilkan oleh diatom. Hal tersebut menunjukkan peran besar diatom bagi ekosistem (Hoek et al., 1998). Peranan utama diatom dan mikroalga lain adalah sebagai produsen tingkat primer bagi zooplankton, cacing, dan moluska (Nurwito, 1989).

Diatom adalah mikroalga uniseluler fotosintetik yang memiliki dinding khas terbuat dari silika. Pola, ukuran, dan ornamentasi dinding sel yang khas menjadi ciri taksonomi jenis-jenis diatom. Diatom memiliki klorofil a, c, alfa, dan betakaroten, serta xantofil (fucoxantin, diadinoxantin, dan diatoxantin) sehingga warnanya menjadi coklat keemasan. Diatom juga dibagi menjadi dua bentuk, yaitu dapat berupa centric diatom maupun pennate diatom. Centric diatom berbentuk simetri radial dan reproduksinya secara oogamy, sedangkan pennate diatom berbentuk kurang lebih simetri bilateral dan bereproduksi secara isogamy (Isnansetyo dan Kurniastuty, 1995). Pembagian diatom atas bentuk dan tipe reproduksi ini juga menjadi ciri taksonomi diatom. Lebih dari 250 genera dengan kurang lebih 100.000 spesies diatom telah ditemukan. Diatom bisa hidup di air laut, air tawar, batu karang, maupun di tanah yang lembab (Hoek et al. , 1998).

Diatom dapat dikultur untuk menghasilkan pakan zooplankton, ikan, udang, serta hewan tambak lain dengan ditumbuhkan secara monokultur maupun polikultur. Secara umum, pada kultur mikroalga dibutuhkan berbagai macam senyawa anorganik baik sebagai hara makro (N, P, $\mathrm{K}, \mathrm{S}, \mathrm{Na}, \mathrm{Si}$, dan $\mathrm{Ca}$ ) maupun hara mikro (Fe, $\mathrm{Zn}, \mathrm{Cu}, \mathrm{Mg}, \mathrm{Mo}, \mathrm{Co}, \mathrm{B}$, dan lain-lain). Setiap unsur hara memiliki fungsi khusus yang tercermin pada pertumbuhan dan kepadatan yang dicapai, tanpa mengesampingkan kondisi lingkungan (Andersen, 2005). Faktor-faktor lingkungan yang berpengaruh terhadap pertumbuhan mikroalga antara lain cahaya, temperatur, salinitas, tekanan osmose, dan $\mathrm{pH}$ air, yang bisa jadi memacu atau menghambat pertumbuhan (Fogg and Thake,1987).

Salah satu organisme perairan yang mempunyai peranan penting adalah diatom. Diatom merupakan produsen primer yang cukup melimpah dan diperlukan sebagai pakan alami yang banyak ditemukan diperairan tawar maupun perairan laut. Diatom merupakan kosmopolitan spesies yang terdistribusi secara luas di seluruh lingkungan akuatik bahkan pada lingkungan darat yang terendam secara berkala seperti permukaan batuan, beberapa jenis tumbuhan dan binatang (Aprisanti et al., 2013).

Silika ini diambil oleh diatom dalam bentuk yang terlarut dalam air, yaitu sebagai 
$\mathrm{Si}(\mathrm{OH}) 4$. Berbagai jenis diatom memerlukan silika dalam jumlah yang berbeda-beda, akibatnya saat terjadi variasi kandungan silika yang terlarut dalam air maka dapat terjadi suksesi diatom, jadi perubahan kandungan silika merupakan salah satu faktor yang menyebabkan suksesi diatom (Werner, 1977).

Silikat $\left(\mathrm{SiO}_{2}\right)$ sudah mulai digunakan oleh para pengkultur Thallasiosira sp. namun sampai saat ini belum dketahui dosis yang efektif penggunaan silikat $\left(\mathrm{SiO}_{2}\right)$ dalam pengkultur Chaetoceros grasillis sehingga dalam penelitin ini dapat diindentifikasikan permasalahan yaitu Berapa dosis yang tepat penggunaan silikat $\left(\mathrm{SiO}_{2}\right)$ untuk menghasilkan pertumbuhan Thallasiosira sp yang optimum, Oleh karena itu tidak mengherankan apabila diatom mempunyai peranan yang sangat penting dalam siklus silika dan karbon di alam sehingga kesinambungan perikanan terjaga (Mann dan Lazier, 2006).

Maka berdasarkan uraian diatas menjadi dasar melatar belakang untuk mengetahui evaluasi kinerja pertumbuhan diatom Thallasiosira sp yang diberi silikat dengan menggunakan media botol dengan berukuran 1 liter, dikarenakan peneliti ingin mengetahui seberapa besarkah pengaruh pertumbuhan diatom Thallasiosira sp yang diberi silikat dengan menggunakan media botol dengan dosis yang berbeda yaitu 0 ppm,3 ppm, 6 ppm, 9 ppm, 12 ppm, 15 ppm.

\section{Rumusan Masalah}

Berdasarkan Latar belakang di atas bahwa Diatom dinding sel nya terdiri dari silika, bersasarkan itu dapat di lihat perbedaan pertumbuhan diatom (Thalassioseira sp) yang di beri dosis silika yang berbeda.

\section{Tujuan Penelitian}

Tujuan dari penelitian ini yaitu :

1. Mengetahui pertumbuhan diatom (Thalasioseira $s p$ ) yang di beri dosis silikat

2. Mengetahui jumlah dosis silikat yang optimum dalam pertumbuhan diatom (Thalasioseira sp)

\section{Manfaat Penelitian}

Hasil penelitian ini diharapkan dapat memberikan data informasi terhadap pertumbuhan 
diatom (Thalassioseira $s p$ ) pada pakan alami jenis fitoplankton.

\section{METODOLOGI PENELITIAN}

\section{Tempat dan Waktu Penelitian}

Penelitian ini akan dilaksanakan pada tanggal 14 April - 1 Mei 2017 bertempat di lab kultur phytoplakton PT Nuansa Ayu Karamba, pulau pramuka Jakarta.

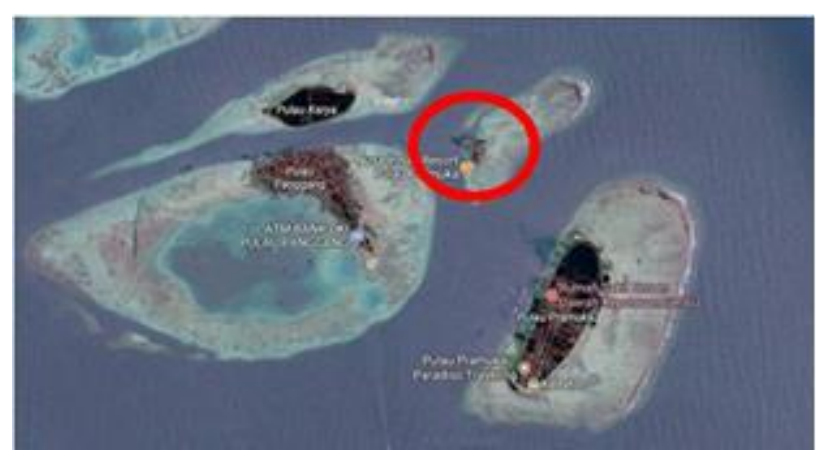

Gambar 1. lokasi penelitian

\section{Alat dan Bahan 3.2.1 Alat}

Tabel 1. Alat yang digunakan :

\section{Bahan}

Tabel 2. Bahan yang digunakan :

\begin{tabular}{|l|l|}
\hline Bahan & Keterangan \\
\hline 1. Silikat & Mineral \\
\hline 2.Bibit phytoplankton & Stater \\
\hline 3. Aquades & Pengenceran \\
\hline 4. Urea & Pupuk \\
\hline 5. TSP & Pupuk \\
\hline 6. FeCl3 & Pupuk \\
\hline 7. T aerasi & Pembagi oksigen \\
\hline 8. Kaporit & Penetral $\mathrm{pH}$ \\
\hline
\end{tabular}

\section{Desain Penelitian}

Penelitian yang terdiri dari 6 perlakuan dengan 3 kali ulangan yaitu:

a. Perlakuan A : Thalassioseira sp diberi Dosis silikat 0 ppm 
b. Perlakuan B : Thalassioseira sp diberi Dosis silikat $3 \mathrm{ppm}$

c. Perlakuan $\mathrm{C}$ : Thalassioseira sp diberi Dosis silikat 6 ppm

d. Perlakuan D : Thalassioseira sp diberi Dosis silikat 9 ppm

e. Perlakuan E : Thalassioseira sp diberi Dosis silikat 12 ppm

f. Perlakuan F : Thalassioseira sp diberi Dosis silikat 15 ppm

Tabel 3. Komposisi silikat, pupuk dan kombinasi kandungan

\begin{tabular}{|l|l|l|l|l|}
\hline & Urea & TSP & FeCL3 & EDTA \\
\hline $0 \mathrm{ppm}$ & $0,1 \mathrm{ml} / \mathrm{l}$ & $0,015 \mathrm{ml} / \mathrm{l}$ & $0,005 \mathrm{ml} / \mathrm{l}$ & 0,002 \\
\hline $3 \mathrm{ppm}$ & $0,1 \mathrm{ml} / 1$ & $0,015 \mathrm{ml} / 1$ & $0,005 \mathrm{ml} / 1$ & 0,002 \\
\hline $6 \mathrm{ppm}$ & $0,1 \mathrm{ml} / 1$ & $0,015 \mathrm{ml} / 1$ & $0,005 \mathrm{ml} / 1$ & 0,002 \\
\hline $12 \mathrm{ppm}$ & $0,1 \mathrm{ml} / 1$ & $0,015 \mathrm{ml} / 1$ & $0,005 \mathrm{ml} / 1$ & 0,002 \\
\hline $15 \mathrm{ppm}$ & $0,1 \mathrm{ml} / 1$ & $0,015 \mathrm{ml} / 1$ & $0,005 \mathrm{ml} / 1$ & 0,002 \\
\hline
\end{tabular}

\section{Prosedur Penelitian}

Penelitian ini dibagi menjadi 3 (tiga) tahapan yaitu, tahap persiapan, tahap pelaksanaan dan tahap analisis. Pada tahapan persiapan dilakukan untuk menyiapkan media kultur Thalassioseira sp. kemudian tahapan pelaksanaan terdiri dari kultur diatom menggunakan silikat sesuai dengan konsentrasi tiap perlakuan, berikut penjabaran tahapan-tahapan yang akan dilakukan selama penelitian:

\section{Persiapan}

Hal-hal yang dilakukan saat persiapan penelitian sebagai berikut:

1. Semua media, perlengkapan aerasi dicuci dengan air kaporit dan dibilas dengan air tawar bersih dan dikeringkan,

2. Persiapan penenceran larutan silikat $(1 \mathrm{ppm}=0.001 \mathrm{ml} / \mathrm{l})$ jadi dosis siikat yang di lakukan pengenceran $3 \mathrm{ppm}=0,003 \mathrm{ml} / \mathrm{l}, 6 \mathrm{ppm}=0,006 \mathrm{ml} / \mathrm{l}, 9 \mathrm{ppm}=0,009 \mathrm{ml} / \mathrm{l}, 12 \mathrm{ppm}=0,012$ $\mathrm{ml} / \mathrm{l}, 15 \mathrm{ppm}=0,015 \mathrm{ml} / \mathrm{l}$, dan pengenceran pupuk yang digunakan UREA $100 \mathrm{ppm}=0.1$ $\mathrm{ml} / \mathrm{l}$, TSP $15 \mathrm{ppm}=0,015 \mathrm{ml} / \mathrm{l}$, FeCL3 $5 \mathrm{ppm}=0,005 \mathrm{ml} / \mathrm{l}$, EDTA $2 \mathrm{ppm}=0,002 \mathrm{ml} / \mathrm{l}$.

3. Pengisian media botol dengan volume 1 liter yang akan digunakan diletakkan diatas meja dengan susunan yang telah ditentukan, isi botol tersebut dengan air laut sebanyak 1 liter 
kemudian botol yang digunakan sebanyak 18 botol ( 6 perlakuan x 3 kali ulangan) dilakukan pemasangan aerasi.

4. Media dimasukkan ke ruangan lab kultur bersuhu dingin untuk menghindari kontak langsung dengan lingkungan dan menjaga suhu agar tetap stabil.

\section{Parameter yang diamati}

\section{Mengkultur Laju Pertumbuhan Fitoplankton}

Pengambilan sampel diatom dilakukan dengan cara mengambil sampel diatom pada substrat dasar di setiap stasiun dengan ukuran 20 x $20 \mathrm{~cm}$. Disiapkan ember yang berisi aquades 1 L, diambil substrat pasir dimasukkan ke dalam ember, kemudian disaring menggunakan saringan bertingkat. Air hasil saringan substrat pasir ditampung di dalam ember dan disaring menggunakan plankton-net. Air yang tertampung dalam plankton-net dipindahkan ke dalam botol sampel plankton dan diberi formalin $40 \%$ hingga konsentrasinya menjadi $4 \%$ dan diberi lugol sebanyak 2-3 tetes (APHA, 1992). Formalin 4\% diproleh dengan menggunakan rumus sebagai berikut:

$\mathrm{V} 1 \mathrm{x} \mathrm{N} 1=\mathrm{V} 2 \times \mathrm{N} 2$

Keterangan: $\quad \mathrm{V} 1=$ Volume botol sampel N1 = konsentrasi formalin yang diinginkan (4\%)

$\mathrm{V} 2$ = volume formalin yang ditambahkan

$\mathrm{N} 2=$ konsentrasi formalin yang ada $(40 \%)$

\section{Menentukan waktu pertumbuhan}

Penentuan pola pertumbuhan fitoplankton, dilakukan dengan penghitungan jumlah sel per mililiter medium setiap jam 10.00 WIB per 24 jam.Contoh diambil dengan pipet tetes steril diteteskan sekitar 0,1-0,5 mL pada Haemositometer, kemudian diamati melalui mikroskop. Bila kepadatan sel masih normal, penghitungan kepadatannya menggunakan rumus :

Jumlah $\frac{\text { sel }}{\mathrm{mL}}=\frac{\text { jumlah sel dalam } 4 \text { kotak }}{\text { jumlah blok }(=4)} \times 10.000$

Bila kepadatan selnya terlalu tinggi, penghitungannya menggunakan rumus: Jumlah sel/mL =Jumlah sel dalam 4 bagian x 4 x 10.000

\section{Kualitas Air}


Parameter kualitas air yang diukur adalah suhu, $\mathrm{pH}$, salinitas, dan DO. Pengukuran dilakukan pada setiap unit percobaan dengan frekuensi setiap hari pada pagi hari pukul 07.00, siang hari pukul 12.00 serta sore hari pukul 17.00 selama penelitian. Alat yang digunakan untuk pengukuran adalah termometer, $\mathrm{pH}$ meter, refraktometer, dan $\mathrm{DO}$ meter.

\section{Analisis Data}

Data-data hasil penelitian diolah menggunakan Regresi Linier Sederhana untuk mengetahui ada atau tidak adanya pengaruh pemberian silikat terhadap kultur diatom Thalassioseira sp. Parameter yang akan dihitung menggunakan uji Anova adalah pertumbuhan, laju pertumbuhan harian.

\section{HASIL DAN PEMBAHASAN}

\section{Hasil dan Pembahasan}

\section{Waktu Pertumbuhan}

Dari data penelitian ini waktu pertumbuhan per ml Thallassiosira sp, dalam wadah percobaan, dapat dilihat pada Tabel 4 dibawah ini:

Tabel 4. Hasil rata-rata laju pertumbuhan sel

\begin{tabular}{|c|c|c|c|c|c|c|}
\hline $\begin{array}{c}\text { Waktu } \\
\text { (sampling) }\end{array}$ & 0 ppm & $\mathbf{3}$ ppm & $\mathbf{6} \mathbf{p p m}$ & $\mathbf{9} \mathbf{p p m}$ & $\mathbf{1 2} \mathbf{p p m}$ & $\mathbf{1 5} \mathbf{p p m}$ \\
\hline $\begin{array}{c}\mathbf{4 - 1 6} \\
\text { april 2017 }\end{array}$ & 276.667 & 540.000 & 786.667 & 853.333 & 996.667 & 1.113 .333 \\
\hline $\begin{array}{c}\mathbf{2 2}-\mathbf{2 4} \\
\text { APRIL } \\
\mathbf{2 0 1 7}\end{array}$ & 258.333 & 536.667 & 787.333 & 840.000 & 986.667 & 1.240 .000 \\
\hline $\begin{array}{c}\text { 29 APRIL } \\
\mathbf{- 1} \text { MEI } \\
\mathbf{2 0 1 7}\end{array}$ & 239.667 & 572.333 & 724.667 & 867.000 & 1.041 .333 & 1.174 .000 \\
\hline
\end{tabular}

Pemberian Silikat dengan dosis 0 ppm, 3 ppm, 6 ppm, 9 ppm,12 ppm dan 15 ppm, diperoleh data pertumbuhan relatif Thalassiosira sp sebagaimana disajikan pada Tabel 4. Hasil yang diperoleh menunjukkan konsentrasi silikat dengan dosis 15 ppm yang paling banyak untuk mendapatkan pertambahan sel paling tinggi dengan pertambahan sel rata-rata sebesar 1.175.778 sel mL-1 hari-1. Selanjutnya berturut-turut diikuti perlakuan $12 \mathrm{ppm}$ dengan pertambahan sel 
rata-rata sebesar 1.008.222 sel mL-1 hari-1, perlakuan 9 ppm dengan pertambahan sel rata-rata sebesar 853.444 sel mL-1hari-1, perlakuan 6 ppm dengan pertambahan sel rata-rata sebesar 766.222 sel mL-1hari-1, perlakuan 3 ppm dengan pertambahan sel rata-rata sebesar 549.667 sel mL-1hari-1 dan control dengan pertambahan sel rata-rata sebesar 258.222 sel mL 1 hari-1.

Hasil analisis ragam menunjukkan perlakuan pemberian dosis pupuk berpengaruh nyata terhadap kepadatan sel Thallassiosira sp (Fhit>Ftab). Hal ini menunjukkan variasi dosis pupuk berpengaruh terhadap tingkat kepadatan sel Thallassiosira sp. Pola pertumbuhan sel mikroalga terdiri dari fase adaptasi (lag phase), fase logaritmik (logarithmic phase), fase penurunan laju pertumbuhan (phase of declining growth rate), fase stasioner (stationary phase), dan fase kematian (death phase) (Bonen \& Doolittle, 1975; Bold \& Wynne, 1985; Panggabean, 2006; Boyer et al., 2009; Fauziah \& Hatta, 2015). Fase logaritmik merupakan tahapan dimana terjadi peningkatan jumlah sel secara logaritmik atau eksponensial. Setelah fase logaritmik terjadi fase stationer, yaitu penambahan jumlah sel-sel mengalami penurunan atau pertumbuhan tidak secara logaritmik. Selanjutnya fase stationer dimana tidak ada penambahan jumlah populasi mikroalga. Selanjutnya terjadi fase kematian (death phase) dimana terjadi penurunan jumlah populasi mikroalga.

Pada Gambar 4 diketahui setiap perlakuan dosis pupuk tidak mengalami fase adaptasi karena sejak hari pertama kepadatan sel telah mengalami pertambahan. Pertumbuhan mikroalga di dalam kultur tidak selalu mengalami fase lag apabila kondisi lingkungan telah sesuai dengan lingkungan sebelumnya (Panggabean, 2006; Setyaningsih et al., 2006).

\section{Kualitas Air}

\section{Suhu Air}

Perubahan suhu air harian selama penelitian dapat dilihat pada Gambar 4. perubahan suhu dari hari ke-1 hingga hari ke -3 diakibatkan karena adanya penyesuaian media terhadap suhu lingkungan. Air pada saat pertama kali dituang dalam wadah media kultur memiliki suhu $35,0^{\circ} \mathrm{C}$. Hal ini dikarenakan adanya proses penembakan sinar UV yang menyebabkan tingginya suhu air 


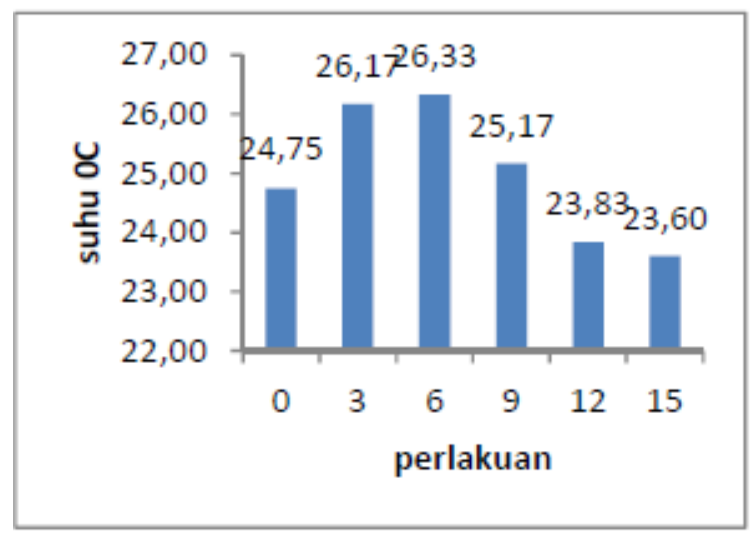

Gambar 4. suhu selama penelitian

Thalassiosira sp memiliki kisaran perubahan suhu anatara 23,6 - 26,33 ${ }^{0} \mathrm{C}$. Kisaran suhu tersebut termasuk ke dalam kisaran suhu optimal bagi pertumbuhan mikroalga yaitu 19,0 - 32,0 ${ }^{\circ} \mathrm{C}$ (Sylvester et al., 2002 dan Cahyaningsih, 2009).

\section{SALINITAS}

Salinitas merupakan salah satu parameter kualitas air yang mempengaruhi tekanan osmotik antara protoplasma sel organik dengan lingkungannya (Rochmady, 2015). Perubahan salinitas pada media kultur dapat dilihat pada Gambar 5 . salinitas awal pada saat kultur diatom adalah 28,0\%o. Kenaikan salinitas media kultur berkorelasi positif terhadap perlakuan. Salinitas ini berkisar antara 28,00-31,33\%o pada perlakuan 15 ppm.

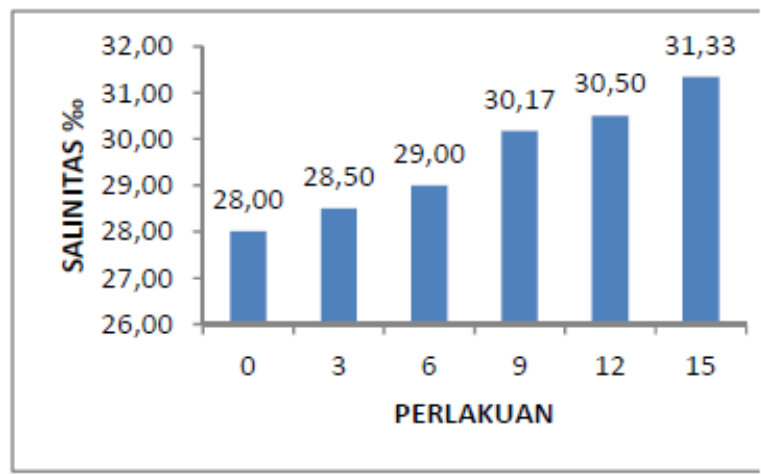

Gambar 5 . salinitas pada saat penelitian

Salinitas yang diamati selama penelitian termasuk ke dalam salinitas optimum bagi pertumbuhan mikroalga 25,0 - 35,0\%o (Sylvester et al., 2002). Kisaran nilai salinitas yang bisa ditoleransi oleh diatom antara 15-34 ppt, pertumbuhan optimalnya pada salinitas 25-29 ppt (Isnansetyo \& Kurniastuty, 1995), salinitas 15-34 ppt dan salinitas optimal 20-29ppt (Winanto,2004). 
Salinitas lebih tinggi atau lebih rendah akan menganggu proses metabolisme sel sehingga pertumbuhan diatom melambat. Jenis diatom umumnya hidup di sekitar permukaan pantai dengan perairan bersifat payau dengan salinitas tidak terlalu tinggi (Rudiyanti, 2011).

\section{DERAJAT KAESAMAN (pH)}

Perubahan derajat keasaman $(\mathrm{pH})$ dalam kultur diatom yang diberi dosis silikat selama 3 hari di ulang sebanyak 3 kali pengamatan cenderung fluktuatif. Perubahan derajat keasaman (pH) pada media kultur dapat dilihat pada Gambar 6. Kisaran perubahan $\mathrm{pH}$ adalah 8,11 - 8, 40 .

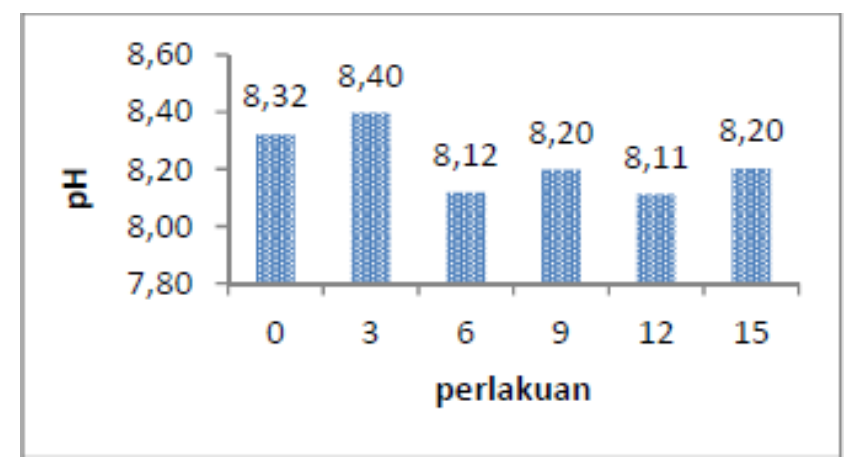

Gambar 6. Derajat Keasaman $(\mathrm{pH})$

Perubahan $\mathrm{pH}$ pada saat kultur mikroalga dapat disebabkan karena adanya perunahan kelarutan CO2 dan mineral di dala media medium pertumbuhan (Suantika, 2009).

\section{KESIMPULAN DAN SARAN}

\section{Kesimpulan}

1. Pengaruh pemberian dosis silikat yang berbeda terhadap pertumbuhan diatom (Thalasiosira) tidak terlalu signifikan. Terdapat perbedaan pertumbuhan oleh masing-masing perlakuan. Hubungan antara kandungan silikat dengan jumlah sel $\mathrm{R}^{2}=96,0 \%$ hal tersebut menjelaskan bahwa rata rata laju pertumbuhan Thallassiosira sp sebesar 96,0 \% artinya Kandungan silikat memiliki peranan penting terhadap jumlah sel diatom.

2. Dari hasil pengamatan tersebut data dilihat dari data di atas pada 15 ppm menghasilkan data pertumbuhan dan nilai rata-rata pertumbuhan data lebih tinggi di badingkan 12 ppm, 9 ppm,6 ppm, 3 ppm, 0 ppm. 


\section{Saran}

Saran untuk melakukan penelitin ini seterusnya bias mencoba dengan nilai silica yang lebih tinggi lagi dati 15 ppm.

\section{DAFTAR PUSTAKA}

Andersen, R.A. (Eds). 2005. Algal culturing techniques. UK: Elsevier Academic Press. p.507

Aprisanti, R., A. Mulyadi dan S. H. Siregar. 2013. Struktur Komunitas Diatom Epilitik Perairan Sungai Senapelan dan Sungai Sail, Kota Pekanbaru. Jurnal Ilmu Lingkungan. Program Pascasarjana Universitas Riau, Pekanbaru. Vol 7 (2) : 243-246.

Barus, T.A. (2002). Pengantar Limnologi. Jurusan Biologi FMIPA Universitas

Basmi, J. 1999. Planktonologi: chrysophyta-diatom, penuntun identifikasi. Fakultas perikanan dan ilmu kelutan. Institut pertanian bogor. Bogor.

Becerril, D.U.H., P.M.G.Sara., dan A.B.C. Sofia. 2009. Morphological variability of the planktonic diatom Thalassiosira delicatula ostenfeld emend. Hasle from the Mexican pacific, in culture conditions. Acta bot. croat. 68 (2): 313-323.

Bold, H. C. \& Wynne, M. J., 1985. Introduction to the algae. New Jersey: Prentice Hall Inc., $720 \mathrm{p}$.

Bonen, L. \& Doolittle, W. F., 1975. On the prokaryotic nature of red algal chloroplasts. Proceedings of the National Academy of Sciences ofthe United States of America, 72(6): 2310-2314, ISSN: 0027-8424, DOI: 10.1073/pnas.72.6.2310.

Boyer, J. N.; Kelble, C. R.; Ortner, P. B. \& Rudnick, D. T., 2009. Phytoplankton bloom status: Chlorophyll a biomass as an indicator of water quality condition in the southern estuaries of Florida, USA. Ecological Indicators, 9(6 SUPPL.): 56-67, ISSN: 1470160X, DOI: 10.1016/j.ecolind.2008.11.013.

Cotton dan Wilkinson. 1989, Kimia Anorganik Dasar. Cetakan Pertama. Jakarta: UI-Press

Darley, W.M. 1982. Alga-biology: a physiological approach. Blackwell Scientific Publication. Edinburg.

Della, V.., Kuhn, I., and Hotza, D., 2002. Rice husk ash as an alternate source for active silica production. Materials Letter, (Desember), 818 - 821 .

Edhy, W.A., P. Januar, dan Kurniawan. 2003. Plankton di lingkungan PT Central pertiwi bahari. Laboraturium central department, aquaculture division PT. central pertiwi bahari. Tulang bawang.

Effendi, H. 2003. Telaah Kualitas Air: Bagi Pengelolaan Sumber Daya dan Lingkungan Periaran. Kanisius: Yogyakarta.

Fauziah, F. \& Hatta, M., 2015. Pengaruh pemberian kascing (bekas cacing) dengan dosis yang berbeda dalam kultur Skeletonema costatum. Acta Aquatica: Aquatic Sciences Journal, 2(1), ISSN: 2406-9825, DOI: 10.29103/AA.V2I1.346.

Fogg, G.E. 1965. Algae Culture and Phytoplankton Ecology. The University of Winconsin Press. Madisson, Milk Wauhe.

Fogg, G.E. and B.Thake. 1987. Algal cultures and phytoplankton ecology, 2nd Ed. The University of Wisconsin Press. England. pp.12-36, 43

Ghofar, A. 1983. Fotosintesa pada diatome. Bulletin peternakan dan perikanan tahun VIII no 1-2 Juni. Fakultas peternakan. UNDIP. Semarang

Hoek, C.V.D., D.G. Mann, H.M. Jahns. 1998.Algae:An Introduction to Phycology. Cambridge 
University Press. UK

Isnansetyo, A. \& Kurniastuty, E., 1995. Teknik kultur Phytoplankton dan Zooplankton. Pakan Alami untuk Pembenihan Organisme Laut. Yogyakarta: Penerbit Kanisius

Jorgensen. 1977. Pengaruh berbagai tingkat intensitas cahaya dan salinitas terhadap pertumbuhan populasi chaetoceros calcitrans. Fakultas peternakan. UNDIP. Semarang.

Mann, K.H. dan J.R.N. Lazier. 2006. Dynamics of marine ecosystem. Hal 33-34. $3^{\text {rd }}$ edition. Blackwell scientific publication. London UK

Nurwito. 1989. Pengaruh Penambahan Silikat pada Medium terhadap Pertumbuhan Chaetoceros gracilis (Diatom). Prosiding seminar Fakultas Biologi UGM. Yogyakarta

Nybakken, J.W. 1993. Biologi Laut; Suatu Pendekatan Ekologis. PT. Gramedia. Jakarta

Pandley, S.N. dan P.S. Triveni. 2005. A textbook of algae. Vikas publishing house PVT LTD. New Delhi.

Panggabean, L.M.G dan Sutomo. 2000. Karakteristik pertumbuhan beberapa jenis diatomae dalam kultur laboratoris. Seminar lustrum IX Fakultas biologi dan kongres I Kabiogama, 22-24 September 2000. Yogyakarta. Puslitbang Oseanologi- LIPI. Jakarta. Indonesia

Panggabean, L. M. G., 2006. Toksin alam dari mikroalgae. Oseana, 31(3):1-12.

Purba, OS. 2008. Tesis. Pengembangan medium untuk peningkatan produktivitas kultur batch diatom laut thalassiosira sp. Institut Teknologi Bandung. Bandung

Rochmady, R., 2015. Analisis parameter oseanografi melalui pendekatan sistem informasi manajemen berbasis web (Sebaran suhu permukaan laut, klorofil-a dan tinggi permukaan laut). AGRIKAN Jurnal Ilmiah Agribisnis dan Perikanan, 8(1): 1-7, ISSN: 19796072

Round, F.E. 1973. The Biology Of Algae. London : Edward Arnold. 278 pp Rudiyanti, S., 2011. Pertumbuhan Skeletonema costatum pada Berbagai Tingkat Salinitas Media. Jurnal Saintek Perikanan,6(2): 69-76.

Sachlan, M. 1980. Planktonologi. Universitas Riau. hlm. 85

Setyaningsih, I.; Panggabean, L. M.; Riyanto, B. \& Nugraheny, N., 2006. Potensi antibakteri diatom laut Skeletonema costatum terhadap bakteri Vibrio sp. Buletin Teknologi Hasil Perikanan, 9(1): 61-71

Soeprobowati, T.R. dan H. Suwarno. 2009. Diatom dan Paleolimnologi: Studi Komparasi Perjalanan Sejarah Danau Lac Saint-Augustine Quebeq-City, Canada 